\title{
- SYSTEM E-ZDROWIA W OPINII PACJENTÓW I PERSONELU MEDYCZNEGO
}

\section{OPINIONS OF PATIENTS AND MEDICAL STAFF ABOUT E-HEALTH SERVICES}

\author{
Anna Jurczak ${ }^{1}$ Jolanta Prażmo², Sylwia Wieder-Huszla¹, Dorota Branecka-Woźniak ${ }^{3}$, \\ Jacek Brodowski ${ }^{4}$, Elżbieta Grochans ${ }^{5}$
}

\author{
Zakład Pielęgniarstwa Specjalistycznego \\ Pomorski Uniwersytet Medyczny w Szczecinie \\ ${ }^{2}$ Studenckie Koło Naukowe \\ Pomorski Uniwersytet Medyczny w Szczecinie \\ ${ }^{3}$ Zakład Zdrowia Prokreacyjnego \\ Pomorski Uniwersytet Medyczny w Szczecinie \\ ${ }^{4}$ Zakład Podstawowej Opieki Zdrowotnej \\ Pomorski Uniwersytet Medyczny w Szczecinie \\ ${ }^{5}$ Zakład Pielęgniarstwa \\ Pomorski Uniwersytet Medyczny w Szczecinie
}

DOI: https://doi.org/10.20883/pielpol.2017.56

\section{STRESZCZENIE}

Wstęp. Technologie informacyjno-komunikacyjne są integralną częścią życia współczesnego człowieka. Znajdują one zastosowanie w usługach medycznych określanych jako obszary e-zdrowia (e-health). Jednym z głównych czynników, który warunkuje efektywne zastosowane obszarów e-zdrowia, jest świadomość oraz wiedza społeczeństwa w tej dziedzinie. Dlatego bardzo istotne jest poznanie opinii potencjalnych użytkowników obszarów e-zdrowia.

Cel. Analiza opinii personelu medycznego oraz pacjentów na temat obszarów e-zdrowia.

Materiał i metody. Badanie opinii na temat przydatności obszarów e-zdrowia przeprowadzono w okresie od 10 lipca do 15 listopada 2015 roku wśród pacjentów i personelu medycznego województwa zachodniopomorskiego (340 osób). Metodą badania był sondaż diagnostyczny, a narzędziem - autorski kwestionariusz ankiety sporządzony w dwóch wersjach - dla pacjentów i personelu medycznego.

Wyniki. W grupie pacjentów $52,10 \%$ stanowiły osoby niezdecydowane do korzystania $z$ usług e-zdrowia. Z tych usług najchętniej korzystają osoby młodsze w wieku 25-39 lat $(52,63 \%)$. Spośród pracowników medycznych chęć korzystania z usługi e-zdrowia zadeklarowało $62,94 \%$ respondentów. Pojęcia z zakresu e-zdrowia zna $68,44 \%$ badanych, termin telemedycyny $-47,20 \%$, zaś z zastosowaniem telemedycyny spotkało się $38,82 \%$ ankietowanych.

Wnioski.

1. Większość ankietowanych zna pojęcie e-zdrowia, jednak dostępność do obszarów e-zdrowia w placówkach jest ograniczona.

2. Akceptacja dla wykorzystania poszczególnych aplikacji w obszarze e-zdrowia jest zróżnicowana. Wyraźnie wyższy stopień niechęci do korzystania z rozwiązań innowacyjnych występuje w grupie pacjentów w starszym wieku.

\begin{abstract}
Introduction. Information and communication technologies (ICT) are an integral part of modern people's lives. They find application in medical practice (defined as e-health services). One of the main factors that determine effectiveness of e-health services is society's awareness and knowledge of these issues. Therefore, it is so important to become acquainted with opinions of potential users on e-health technology.

Aim. Analyze opinions of patients and medical staff about e-health services.

Material. This survey-based study on the usefulness of e-health services was conducted from 10 July to 15 November 2015 among patients and medical staff in West Pomeranian Voivodeship (340 people). The research instrument applied in this study was the author's questionnaire in two versions - one for patients and one for medical staff.

Results. In the group of patients, $52.10 \%$ of respondents were undecided whether to use e-health services. The most eager to use them were $25-39$ year olds $(52.63 \%)$. In the group of medical workers, $62.94 \%$ of respondents claimed that they would use e-health tools. $68.44 \%$ of respondents were familiar with e-health related issues, $47.20 \%$ knew the term 'telemedicine', and $38.82 \%$ used telemedicine in practice.

Conclusions.

1. The majority of the respondents know the term 'e-health' but access to e-health services in medical centers is limited.

2. Acceptance of various e-health applications is varied. Older patients are noticeably more reluctant to use innovative solutions.
\end{abstract}


3. Dostęp do materiałów edukacyjnych oraz rozwiązania wspomagające usługi medyczne, tj. wykorzystanie Internetu do odnowienia recepty, rejestracji na wizyty, badania, rehabilitacje, uzyskują najwyższą akceptację, zarówno wśród pacjentów, jak i personelu.

SŁOWA KLUCZOWE: e-zdrowie, telemedycyna, pacjenci, personel medyczny.

\section{Wprowadzenie}

Ochrona zdrowia z jednej strony korzysta z innowacji technologicznych, a z drugiej strony jest dziedziną o podejściu zachowawczym dla akceptacji nowoczesnych form świadczenia usług. Implikacją takiego stanu rzeczy jest utrwalona postawa w społeczeństwie osobistego kontaktu i zaufania panującego pomiędzy pracownikiem ochrony zdrowia a pacjentem. Wykorzystanie nowych technologii informacyjno-komunikacyjnych burzy ten paradygmat [1]. Zastosowanie technologii informacyjno-komunikacyjnych tworzy jednak nowe możliwości na rynku usług medycznych. Wdrażanie systemów e-zdrowia ma na celu wspieranie efektywności świadczonych usług oraz poprawienie infrastruktury opieki zdrowotnej. W aspekcie makroekonomicznym e-zdrowie jest jednym z podstawowych elementów zapewnienia wzrostu gospodarczego. Rozwiązania te determinują jakość, dostępność i efektywność usług w obszarze ochrony zdrowia. Finalnie mają poprawić dostępność, obniżyć koszty społeczne na opiekę zdrowotną oraz poprawić jakość opieki medycznej [2]. Wykorzystanie e-zdrowia może przynieść korzyści pacjentom, instytucjom, pracownikom opieki zdrowotnej. W przypadku efektywnego użytkowania obszarów e-zdrowia podejście do opieki zdrowotnej jest bardziej spersonalizowane i zorientowane na pacjenta oraz daje możliwość dostosowania do aktualnych trendów, potrzeb, zwiększa wydajność i skuteczność, a także pomaga eliminować liczbę błędów i skracać długość hospitalizacji pacjentów. Dostęp do informacji, usług, wykorzystanie mediów społecznościowych w sferze zdrowia sprzyjają podniesieniu jakości życia, integracji społeczno-gospodarczej, równości oraz wzmocnieniu pozycji pacjenta [3].

Rozwój nowoczesnych technologii przyczynił się do nowego spojrzenia na pacjenta jako partnera w procesie leczenia. Staje się on aktywnym uczestnikiem sprawowania opieki, zdolnym do podejmowania decyzji odnośnie jego stanu zdrowia oraz świadomym konsekwencji, jakie wynikają z podjętych decyzji. Koniecznym warunkiem tego stanu jest dostęp do informacji zdrowotnych. Należy podkreślić, że wiedza pacjentów z za-
3. Access to educational resources and solutions supporting medical services, such as using the Internet to renew prescriptions, to make an appointment with the doctor, to make an appointment for examination or rehabilitation meet with the highest acceptance of both patients and medical workers.

KEYWORDS: e-health, telemedicine, patients, medical staff.

kresu medycyny, ich świadomość, a także wymagania wobec ośrodków udzielających świadczenia i lekarzy są wielokrotnie kształtowane przez elektroniczne media, zwłaszcza Internet. Wiele ośrodków medycznych oferuje swoim pacjentom możliwość elektronicznej obsługi. Obszary e-zdrowia (e-health) obejmują swoim zakresem usługi zdrowotne on-line typu wypisywanie recept (e-prescribing), rejestracja (e-registration), wysyłanie krótkich tekstowych wiadomości, które przypominają o obowiązku wzięcia koniecznych leków czy bliskim terminie wizyty (SMS reminders), otrzymywanie krótkich zleceń od lekarza, jak też efektów przeprowadzonych badań (e-mail, SMS), możliwość dostępu do dokumentacji zdrowotnej (electronic health record - EHR). Innym rodzajem usług są usługi telemetryczne w formie telekonsultacji z pielęgniarką/lekarzem, a także telemonitorowanie parametrów stanu zdrowia pacjentów oraz ich zachowań, m.in. tele-EKG, zdalne monitorowanie poziomu glukozy, ciśnienia tętniczego, temperatury, masy ciała, telespirometria, czujniki ruchu, detektory upadków, telemedyczny system do zdalnej kontroli zażywania leków [4, 5].

\section{Cel pracy}

Analiza opinii personelu medycznego oraz pacjentów na temat obszarów e-zdrowia.

\section{Materiał i metody}

Badanie opinii na temat przydatności obszarów e-zdrowia przeprowadzono w okresie od 10 lipca do 15 listopada 2015 roku wśród pacjentów i personelu medycznego województwa zachodniopomorskiego (340 osób). W grupie personelu medycznego ankietę wypełniło 170 osób, w większości były to kobiety $(91,18 \%)$, w wieku od 40 do 59 lat $(64,12 \%)$, z wykształceniem wyższym (67,06\%), z zawodu pielęgniarkalpielęgniarz o stażu pracy $15-29$ lat $(48,82 \%)$, nieposiadający specjalizacji (64,71\%). Wśród innych zawodów wskazywanych wśród respondentów były m.in.: lekarz, położna, ratownik medyczny, opiekun medyczny. Z kolei w grupie pacjentów ankietę wypełniło 170 osób z przewagą kobiet $(65,88 \%)$, w wieku $40-59$ lat $(44,12 \%)$, z wykształ- 
ceniem średnim (43,53\%), mieszkańcy miast powyżej 100 tys. mieszkańców (25,88\%). Metodą badania był sondaż diagnostyczny, a narzędziem - autorski kwestionariusz ankiety sporządzony w dwóch wersjach dla pacjentów i personelu medycznego. Kwestionariusz ankiety zawierał 51 pytań dotyczących wykorzystania technologii informacyjnych i komunikacyjnych dla celów ogólnych, opinii o e-zdrowiu, dostępności do systemów e-zdrowia, akceptacji dla wykorzystania systemów, barier i korzyści oraz wykorzystania i znaczenia systemów. Analizę statystyczną wyników przeprowadzono za pomocą programu Statistica v 12 pakiet zaawansowany oraz Excel 2007. Potwierdzające się zależności w odpowiedziach personelu medycznego oraz pacjentów przedstawiono w formie tabel łącznie z wyliczoną statystyką $\chi 2$ (chi-kwadrat)1 oraz p-value2, przy założonym poziomie istotności $\alpha=0,05$.

\section{Wyniki}

W badanej grupie pacjentów 52,1\% stanowiły osoby niezdecydowane do korzystania z usług e-zdrowia. Z usług tych najchętniej korzystają osoby najmłodsze w wieku 25-39 lat (52,6\%), najmniejsze zainteresowanie wykazali pacjenci w wieku 60 lat i powyżej (10,5\%). W zakresie korzystania z systemów e-zdrowie wykazano istnienie różnicy istotnej statystycznie w zależności od przynależności do poszczególnych grup wiekowych (Tabela 1).

Tabela 1. Chęć korzystania z systemów e-zdrowia wśród pacjentów w zależności od wieku

Table 1. The will of using e-health services among patients, according to their age

\begin{tabular}{|c|c|c|c|}
\hline $\begin{array}{c}\text { Przedziały wiekowe/ } \\
\text { Age ranges }\end{array}$ & $\begin{array}{l}\text { Chcę korzystać } \\
\text { z usług } \\
\text { e-zdrowia/ } \\
\text { I want to use } \\
\text { e-health } \\
\text { services }\end{array}$ & $\begin{array}{l}\text { Nie chcę } \\
\text { korzystać } \\
\text { z usług } \\
\text { e-zdrowia/ } \\
\text { Idon't want to } \\
\text { use e-health } \\
\text { services }\end{array}$ & $\begin{array}{c}\text { Nie wiem, czy } \\
\text { chcę korzystać } \\
\text { z usług } \\
\text { e-zdrowia/ } \\
\text { I don't know } \\
\text { if I want to } \\
\text { use e-health } \\
\text { services }\end{array}$ \\
\hline Do 24 lat/Up to 24 years & $41,7 \%$ & $16,7 \%$ & $41,7 \%$ \\
\hline 25-39 lat/25-39 years & $52,6 \%$ & $2,6 \%$ & $44,7 \%$ \\
\hline 40-59 lat/40-59 years & $30,0 \%$ & $22,0 \%$ & $48,0 \%$ \\
\hline $\begin{array}{c}60 \text { i więcej lat/60 years or } \\
\text { more }\end{array}$ & $5,3 \%$ & $10,5 \%$ & $84,2 \%$ \\
\hline Ogółem/Total & $34,5 \%$ & $13,5 \%$ & $52,1 \%$ \\
\hline \multicolumn{4}{|c|}{ Chi^2 Pearsona/Pearson's Chi^2:19,6195, $\mathrm{df}=6, \mathrm{p}=0,003236$} \\
\hline
\end{tabular}

Źródło: badania własne

Source: author's own materials

Spośród pracowników medycznych chęć korzystania z usług e-zdrowia zadeklarowało $62,9 \%$ respondentów. Wykazano duże niezdecydowanie pracowników w zakresie korzystania z nowoczesnych technologii informacyjnych, sięgające aż 40,5\% (Tabela 2).
Tabela 2. Korzystanie z systemów e-zdrowia wśród pracowników medycznych

Table 2. Using e-health services among medical workers

\begin{tabular}{cc}
\hline $\begin{array}{c}\text { Chęć korzystania z usług „e-zdrowie”/ } \\
\text { Willingness to use e-health services }\end{array}$ & $\%$ \\
\hline Tak/Yes & 62,9 \\
Nie/No & 14,7 \\
Nie wiem/l don't know & 40,5 \\
\hline
\end{tabular}

Źródło: badania własne

Source: author's own materials

Ankietowanym zadano pytania dotyczące znajomości pojęć z zakresu e-zdrowia oraz możliwości ich zastosowania. Pojęcia z zakresu e-zdrowia znało $68,4 \%$ badanych, znacznie częściej pracownicy medyczni $(78,1 \%)$ niż pacjenci $(58,8 \%)$. Termin: telemedycyna znało tylko 47,2\% badanych. Podobnie częściej nieznana dla badanych jest telekardiologia (77,9\%), e-karta $(71,5 \%)$, zastosowanie telemedycyny $(61,2 \%)$. We wszystkich obszarach znajomości pojęć oraz kontaktu z usługami e-zdrowia wykazano istnienie różnic istotnych statystycznie pomiędzy grupą pacjentów oraz personelem medycznym (Tabela 3).

Tabela 3. Znajomość pojęć oraz kontakt z usługami z obszarów e-zdrowia Table 3. The knowledge of conceptions and the contact with e-health services

\begin{tabular}{ccc}
\hline $\begin{array}{c}\text { Status/ } \\
\text { Status }\end{array}$ & $\begin{array}{c}\text { Znajomość pojęcia e-zdrowia/ } \\
\text { Familiarity with the e-health concept } \\
\text { tak/yes }\end{array}$ & nie/no \\
\hline $\begin{array}{c}\text { Personel medyczny/ } \\
\text { Medical staff }\end{array}$ & $78,1 \%$ & $21,9 \%$ \\
Pacjent/Patient & $58,8 \%$ & $41,2 \%$ \\
Ogółem/Total & $68,4 \%$ & $31,6 \%$
\end{tabular}

Chi^2 Pearsona/Pearson's Chi^2: 14,5885, df=1, $\mathrm{p}=0,000134$

$\begin{array}{ccc}\text { Status/ } & \begin{array}{c}\text { Znajomość pojęcia telemedycyna/ } \\ \text { Familiarity with the telemedicine concept } \\ \text { tak/yes }\end{array} & \text { nie/no }\end{array}$

Chi^2 Pearsona/Pearson's Chi^2: 35,1218, df=1, $p=0,000000$

\begin{tabular}{|c|c|c|}
\hline \multirow{2}{*}{$\begin{array}{l}\text { Status/ } \\
\text { Status }\end{array}$} & \multicolumn{2}{|c|}{$\begin{array}{l}\text { Kontakt z telekardiologią/ } \\
\text { Contact with telecardiology }\end{array}$} \\
\hline & tak/yes & nie/no \\
\hline $\begin{array}{l}\text { Personel medyczny/ } \\
\text { Medical staff }\end{array}$ & $34,7 \%$ & $65,3 \%$ \\
\hline Pacjent/Patient & $9,4 \%$ & $90,6 \%$ \\
\hline Ogółem/Total & $22,1 \%$ & $77,9 \%$ \\
\hline
\end{tabular}

Chi^2 Pearsona/Pearson's Chi^2: 31,6307, df=1, p=0,000000

$\begin{array}{ccc}\text { Status/ } & \begin{array}{c}\text { Kontakt z innymi usługami w obszarze telemedycyny/ } \\ \text { Contact with other telemedicine services } \\ \text { tak/yes }\end{array} & \text { nie/no } \\ \text { Personel medyczny/ } \\ \text { Medical staff }\end{array}$




\begin{tabular}{|c|c|c|}
\hline Pacjent/Patient & $0,0 \%$ & $100,0 \%$ \\
\hline Ogółem/Total & $2,9 \%$ & $97,1 \%$ \\
\hline \multicolumn{3}{|c|}{ Chi^2 Pearsona/Pearson's Chi^2: 10,3030, df $=1, p=0,001328$} \\
\hline \multirow{2}{*}{$\begin{array}{l}\text { Status/ } \\
\text { Status }\end{array}$} & \multicolumn{2}{|c|}{$\begin{array}{l}\text { Kontakt z e-kartą ubezpieczenia/ } \\
\text { Contact with an insurance e-card }\end{array}$} \\
\hline & tak/yes & nie/no \\
\hline $\begin{array}{l}\text { Personel medyczny/ } \\
\text { Medical staff }\end{array}$ & $37,6 \%$ & $62,3 \%$ \\
\hline Pacjent/Patient & $19,4 \%$ & $80,6 \%$ \\
\hline Ogółem/Total & $28,5 \%$ & $71,5 \%$ \\
\hline \multicolumn{3}{|c|}{ Chi^2 Pearsona/Pearson's Chi^2: 13,8619, df=1, $p=0,000197$} \\
\hline \multirow{2}{*}{$\begin{array}{l}\text { Status/ } \\
\text { Status }\end{array}$} & \multicolumn{2}{|c|}{$\begin{array}{l}\text { Kontakt z zastosowaniem telemedycyny/ } \\
\text { Contact with telemedicine applications }\end{array}$} \\
\hline & tak/yes & nie/no \\
\hline $\begin{array}{l}\text { Personel medyczny/ } \\
\text { Medical staff }\end{array}$ & $31,8 \%$ & $68,2 \%$ \\
\hline Pacjent/Patient & $45,9 \%$ & $54,1 \%$ \\
\hline Ogółem/Total & $38,8 \%$ & $61,2 \%$ \\
\hline $\mathrm{Chi}^{\wedge} 2 \mathrm{Pe}$ & in & 007560 \\
\hline
\end{tabular}

Źródło: badania własne

Source: author's own materials

Najwyższą akceptację respondenci deklarowali dla dostępu przez aplikacje e-zdrowia do materiałów edukacyjnych dostosowanych do potrzeb pacjenta $(48,8 \%)$, co potwierdzają zarówno pacjenci, jak i personel. Akceptację wykorzystania Internetu do rejestracji na wizyty lekarskie i pielęgniarskie potwierdza prawie połowa $(49,4 \%)$ personelu medycznego, natomiast wśród pacjentów tylko $28,8 \%$ badanych. W zakresie akceptacji dla wykorzystania aplikacji w obszarze e-zdrowia - możliwości dostępu przez aplikację e-zdrowia do materiatów edukacyjnych dostosowanych do potrzeb pacjenta $(p=0,033879)$ oraz wykorzystania Internetu do rejestracji na wizyty lekarskie i pielęgniarskie $(p=0,000003)$ - wykazano istnienie istotnej różnicy pomiędzy pacjentami i personelem medycznym (Tabela 4).

Tabela 4. Akceptacja dla wykorzystania aplikacji w obszarze e-zdrowia Table 4. Acceptance for applications usage in e-health

\begin{tabular}{|c|c|c|c|c|c|}
\hline & $\begin{array}{l}\text { Zdecy- } \\
\text { dowanie } \\
\text { nie/ } \\
\text { Definitely } \\
\quad \text { not }\end{array}$ & $\begin{array}{l}\text { Raczej } \\
\text { nie/ } \\
\text { Rather } \\
\text { not }\end{array}$ & $\begin{array}{l}\text { Nie jestem } \\
\text { pewna/y/ } \\
\text { I'm not } \\
\text { sure }\end{array}$ & $\begin{array}{l}\text { Raczej tak/ } \\
\text { Rather yes }\end{array}$ & $\begin{array}{l}\text { Zdecydo- } \\
\text { wanie tak/ } \\
\text { Definitely } \\
\quad \text { yes }\end{array}$ \\
\hline Status/Status & \multicolumn{5}{|c|}{$\begin{array}{l}\text { Akceptacja możliwości dostępu przez aplikacje } \\
\text { e-zdrowia do materiałów edukacyjnych dostoso- } \\
\text { wanych do potrzeb pacjenta/Acceptance of the } \\
\text { possibility of access to educational resources through } \\
\text { e-health application adjusted to patients' needs }\end{array}$} \\
\hline $\begin{array}{l}\text { Personel medyczny/ } \\
\text { Medical staff }\end{array}$ & $1,8 \%$ & $2,9 \%$ & $5,9 \%$ & $34,1 \%$ & $55,3 \%$ \\
\hline Pacjent/Patient & $1,8 \%$ & $5,9 \%$ & $14,1 \%$ & $35,9 \%$ & $42,3 \%$ \\
\hline Ogółem/Total & $1,8 \%$ & $4,4 \%$ & $10,0 \%$ & $35,0 \%$ & $48,8 \%$ \\
\hline
\end{tabular}

\begin{tabular}{cccccc} 
Status/Status & $\begin{array}{c}\text { Akceptacja wykorzystania Internetu do rejestracji na } \\
\text { wizyty lekarskie i pielegniarskie/Acceptance of the } \\
\text { possibility of making appointments with the doctor or } \\
\text { the nurse via the Internet }\end{array}$ \\
\hline $\begin{array}{c}\text { Personel medyczny/ } \\
\text { Medical staff }\end{array}$ & $2,3 \%$ & $3,5 \%$ & $9,4 \%$ & $35,3 \%$ & $49,4 \%$ \\
Pacjent/Patient & $1,8 \%$ & $4,7 \%$ & $32,3 \%$ & $32,3 \%$ & $28,8 \%$ \\
Ogółem/Total & $2,1 \%$ & $4,1 \%$ & $20,9 \%$ & $33,8 \%$ & $39,1 \%$ \\
Chi^2 Pearsona/Pearson's Chi^2: 31,2790, df=4, p=0,000003 \\
\hline
\end{tabular}

Źródło: badania własne

Source: author's own materials

\section{Dyskusja}

Technologie informacyjno-komunikacyjne wywierają ogromny wpływ na życie współczesnego człowieka. Znajdują one coraz więcej zastosowań i są coraz bardziej powszechne, co wiąże się z postępem cywilizacyjnym. Rozwój nowych technologii wykreował, poprzez stworzenie obszarów e-zdrowia, nowe możliwości dla pacjentów, personelu medycznego oraz systemów opieki zdrowotnej.

Wyniki badań Diagnozy społecznej 2011 w polskiej populacji donoszą, że odsetek gospodarstw domowych, które akceptują usługi medyczne przez Internet, w przypadku dostępu do formularzy i informacji wynosił $49,1 \%$, a w sytuacji realizacji całej usługi przez Internet - 29,8\% [6]. Z badań własnych wynika, że chęć korzystania z usług e-zdrowia deklarują najczęściej pacjenci w przedziale 25-39 lat, zamieszkujący miasta od 10 tys. do 100 tys. mieszkańców. Niepewność i obawy osób starszych przed korzystaniem z tego typu usług mogą być spowodowane brakiem wiedzy i/lub biegłej umiejętności posługiwania się nowoczesnymi technologiami oraz oporami przed nowościami - różnią się tym do ludzi młodych, którzy nie mają problemów z wdrażaniem w życie nowych technologii.

Moick i wsp. w przeprowadzonych wśród niemieckich lekarzy badaniach dotyczących wykorzystania Internetu w celu komunikacji z pacjentami (badania w skali 7-punktowej, gdzie 7 oznaczało „zdecydowane tak”) uzyskali wynik średni na poziomie 4,02 [7]. Przeprowadzone w Szwecji przez Gund i wsp. wśród pracowników ochrony zdrowia badania dotyczące opinii na temat wykorzystywania technologii informacyjno-komunikacyjnych wskazały pozytywne opinie w chwili obecnej-63\% - i w przyszłości - 96\% [8]. Z kolei zespół Duplaga w badaniach przeprowadzonych wśród lekarzy wykazał dość wysoką świadomość dostępności do obszarów e-zdrowia. Powszechność stron internetowych i zintegrowanego systemu informacyjnego w placówkach szpitalnych deklarowało odpowiednio 93\% i 80\% lekarzy [9]. Podobne wyniki dotyczące dostępności ob- 
szarów e-zdrowia uzyskano w sondażu przeprowadzonym w szpitalach na terenie województwa łódzkiego przez Kaczmarską-Krawczak [10]. W materiale własnym w grupie badanych pracowników medycznych chęć korzystania z usług deklarowała ponad połowa respondentów - 62,9\%. Zaobserwowano jednocześnie duże niezdecydowanie pracowników - 40,5\% - w zakresie korzystania z nowoczesnych narzędzi, co może sugerować brak wiedzy na temat obszarów e-zdrowia. Wynik ten jest niepokojący, zważywszy na rozwój technologii i starzejące się społeczeństwo, które wymaga wzmożonej opieki medycznej.

Badania Duplagi wskazały, że z terminem: telemedycyna spotkało się 32,1\% ankietowanych [9]. Wynik ten jest zbieżny z badaniami własnymi.

Według Czerwińskiej oraz Duplagi Internet stanowi obecnie główne źródło pozyskiwania informacji dotyczących zdrowia, chorób i metod leczenia [9, 11].

W badaniach własnych respondenci najczęściej aplikację e-zdrowia wykorzystywali do uzyskania materiałów edukacyjnych (48,8\%) oraz rejestracji na wizyty lekarskie i pielęgniarskie (39,1\%). Wyniki oceny akceptacji dla wykorzystania obszarów e-zdrowia są zbieżne z wynikami badań przeprowadzonych przez Duplagę wśród lekarzy i pacjentów z chorobami przewlekłymi [9]. Wiedza w zakresie zagadnień zdrowotnych zdobywana przez pacjentów jest dość zróżnicowana. Według personelu medycznego z jednej strony wzrastają kompetencje informacyjne pacjentów, z drugiej zaś strony materiały internetowe stanowią potencjalne źródło problemów [12].

Systemy informatyczne w opiece zdrowotnej w Polsce są słabo rozwinięte, choć próbujemy nadążać za światowymi trendami w tej dziedzinie. Niechęć do wykorzystywania nowoczesnych technologii informacyjno-komunikacyjnych może być odzwierciedleniem tradycyjnego podejścia do kontaktu między pacjentem a personelem medycznym - może być wynikiem przekonania, że tylko bezpośrednia relacja zapewni poczucie bezpieczeństwa i rzetelną poradę.

\section{Wnioski}

1. Większość ankietowanych zna pojęcie e-zdrowia, jednak dostępność do obszarów e-zdrowia w placówkach jest ograniczona.

2. Akceptacja dla wykorzystania poszczególnych aplikacji w obszarze e-zdrowia jest zróżnicowana. Wyraźnie wyższy stopień niechęci do korzystania z rozwiązań innowacyjnych występuje w grupie pacjentów w starszym wieku.

3. Dostęp do materiałów edukacyjnych oraz rozwiązania wspomagające usługi medyczne, tj. wykorzystanie Internetu do odnowienia recepty, rejestracji na wizyty, badania, rehabilitacje, uzyskują najwyższą akceptację, zarówno wśród pacjentów, jak i personelu.

\section{Piśmiennictwo}

1. Fieschi M. Information technology is changing the way society sees health care delivery. Int J Med Inform. 2002; 66: 85-93.

2. Czerwińska M. E-health as a key element forming the competitive advantage in helth. W: Bojar E, Słoniec $\mathrm{J}$ (red.). Sustainable development in the regions and countries: management and marketing. Lublin: Politechnika Lubelska; 2014: 101-109.

3. Czerwińska M. Narzędzia e-zdrowia jako instrumenty poprawiające dostęp do usług medycznych w regionie. Nierówności Społeczne a Wzrost Gospodarczy. 2015; 43: 173-185.

4. Bujnowska-Fedak MM, Tomczak M. Innowacyjne aplikacje telemedyczne i usługi e-zdrowia w opiece nad pacjentami w starszym wieku. Zdr Publ Zarz. 2013; 11: 302-317.

5. Maciura $t$, Lasek P, Iwanicka-Maciura A. Koncepcja systemu telemedycznego z komunikacją głosową służącego do przypominania i zdalnej kontroli zażywania leków przez pacjentów geriatrycznych i psychiatrycznych. Prz Elektrotech. 2014; 5: 118-121.

6. Duplaga M. Acceptance of Internet-Based Health Care Services Among Households in Poland: Secondary analysis of a population-based survey. J Med Internet Res. 2012; 14: 164.

7. Moick M, Terlutter R. Physicians' motives for professional Internet use and differences in attitudes toward the internet-informed patiend, physician-patient communication, and prescribing behavior. Med. 2012: 1(2): e2.

8. Gund A, Lindecrantz K, Schaufelberger M et al. Attitudes among healthcare professionals towards ICD and home follow-up in chronic heart failure care. BMC Med Inform Dec Making. 2012; 12: 138.

9. Duplaga $\mathrm{M}$. The acceptance of e-health solutions among patients with chronic respiratory conditions. Telemed J E Health. 2013; 19: 689-691.

10. Kaczmarska-Krawczak J. Zarządzanie informatyzacją w procesach restrukturyzacji jednostek ochrony zdrowia. ZiF. 2013; 1: 245-256.

11. Czerwińska M. Postawy wobec e-zdrowia i opinie na jego temat w grupie studentów kierunku zdrowie publiczne. Rocz Kolegium Analiz Ekonom. 2013; 29: 539-551.

12. Ahmad F, Hudak PL, Bercovitz K et al. Are Physicians Ready for Patients with Internet-Based Health Information? J Med Internet Res. 2006; 8(3): 22.

Artykuł przyjęty do redakcji: 15.09.2016 Artykuł przyjęty do publikacji: 16.02.2017

Źródło finansowania: Praca nie jest finansowana z żadnego źródła. Konflikt interesów: Autorzy deklarują brak konfliktu interesów.
Adres do korespondencji:
Anna Jurczak
ul. Żołnierska 48
71-210 Szczecin
tel.: 914800910
e-mail: jurczak@op.pl
Zakład Pielęgniarstwa Specjalistycznego
Pomorski Uniwersytet Medyczny w Szczecinie 